\title{
Determinants of success of coronary angioplasty in patients with a chronic total occlusion: a multiple logistic regression model to improve selection of patients
}

\author{
Kim H Tan, Neil Sulke, Nick A Taub, Elizabeth Watts, Sheila Karani, Edgar Sowton
}

\begin{abstract}
Objective-To study the determinants of success of coronary angioplasty in patients with chronic total occlusions, and to formulate a multiple logistic regression model to improve selection of patients.
\end{abstract}

Design-A retrospective analysis of clinical and angiographic data on a consecutive series of patients.

Patients-312 patients (mean age 55, range 31 to 79 years, $86 \%$ men) who underwent coronary angioplasty procedure for a chronic total occlusion between 1981 and 1992.

Results-Procedural success was achieved in 191 lesions $(61 \cdot 2 \%)$. A major complication occurred in six patients $(1 \cdot 9 \%)$. Multiple stepwise logistic regression analysis identified the presence of bridging collaterals ( $p<0.001)$, the absence of a tapered entry configuration $(p<0.001)$, estimated duration of occlusion of greater than three months $(p=0 \cdot 001)$, and a vessel diameter of less than $3 \mathrm{~mm}$ $(p=0.003)$ as independent predictors of procedural failure. The logistic regression model was used to classify patients into groups of high, intermediate, and low probability of procedural success with cut off points of $70 \%$ and $30 \%$. The predictive value for procedural success (probability $\geqslant 70 \%$ ) was $91 \%$ (95\% confidence intervals (95\% CI) $83 \%$ to $96 \%)$ and predictive value for procedural failure (probability <30\%) was $81 \%(95 \%$ CI $64 \%$ to $92 \%)$.

Conclusions-Percutaneous transluminal coronary angioplasty of chronic total occlusions is associated with a low risk of acute complication. Procedural success is influenced by easily identifiable clinical and angiographic features and the multiple regression model described may help to improve selection of patients.

(Br Heart F 1993;70:126-131)

Since the introduction of percutaneous transluminal coronary angioplasty by Gruentzig in $1978,{ }^{1}$ the procedure has been applied to increasingly complex lesions including occluded vessels. ${ }^{23}$ Coronary angioplasty of chronic total occlusions is recognised to have a lower primary success rate ranging from $53 \%$ to $73 \%,{ }^{4-6}$ and contributes to the failure to achieve complete revascularisation among many patients with multivessel disease. ${ }^{78}$ Despite this relatively low initial success rate, recanalisation of chronic total occlusions by coronary angioplasty has become an accepted procedure and the prevalence has increased from about $2 \%$ to $10 \%$ of the total number of coronary angioplasties performed in large centres. ${ }^{9}$ At present, the ability to predict the likelihood of procedural success for a particular lesion is poor. Various clinical and angiographic indices have been shown to be related to procedural success rates although previous reports have reached conflicting conclusions. ${ }^{10-12}$ If a statistical model that accurately predicted probability of procedural success on the basis of simple clinical and angiographic factors was available, this would have important implications for the selection of lesions for coronary angioplasty.

This study reports on the acute success and complication rates of coronary angioplasty of chronic total occlusions on 312 consecutive patients. It also describes a multiple logistic regression model incorporating clinical and angiographic data to predict probability of procedural success for a particular lesion.

\section{Patients and methods}

ANGIOPLASTY PROCEDURE

Coronary angioplasty was performed according to a previously described protocol. ${ }^{13}$ More than $60 \%$ of the procedures were performed by a single operator. Steerable guide wire systems have been in use since 1984. The technique used to dilate total coronary occlusions differed depending on the operator but essentially consisted of movable guide wires of increasing stiffness and low profile dilatation balloons, which were exchanged for larger balloons as necessary. In some cases, "balloon on the wire" or the Magnum-Meier system were used. ${ }^{14}$ Axial strength and stability were improved by advancing the balloon catheter to the point of occlusion to splint the guide wire. Deep guide catheter engagement to obtain a stable ostial position was often necessary for adequate support. Once the guide wire was across the occluded segment, its intraluminal course beyond the occlusion was confirmed by either its easy manoeuvrability or antegrade contrast flow around the guide wire. If the position was still uncertain, contralateral angiography was performed by the left femoral approach. During multivessel coronary angioplasty, the occluded vessel was usually attempted first. 
PATIENTS

Between 1981 and 1992, 312 consecutive patients underwent a first coronary angioplasty of a chronic total occlusion at our institution. Patients who had had a myocardial infarction within two weeks of coronary angioplasty were excluded. The decision to dilate a chronically occluded lesion was based on the expectation that restoring antegrade flow would improve ischaemic symptoms or left ventricular function. This implied the presence of viable myocardium, usually the result of collaterals that are capable of maintaining tissue viability. We defined total occlusion as $100 \%$ narrowing of luminal diameter with absence of a visible intraluminal channel. This included vessels with no opacification of the distal segment and vessels with faint distal opacification through antegrade or retrograde collaterals.

The mean (SD) age was 55 (9) (range 31 to 79$)$ years, and $267(86 \%)$ were men. The median duration of occlusion was six months (range up to 156 months). The estimated duration of occlusion was less than three months in 87 patients $(28 \%)$, between three and six months in 66 patients (21\%), between six and 12 months in 66 patients $(21 \%)$, more than 12 months in 62 patients $(20 \%)$, and could not be established in 31 patients $(10 \%)$. Two hundred and five patients $(66 \%)$ had a history of previous myocardial infarction and 137 (44\%) had impaired left ventricular function with an ejection fraction of $<45 \%$ assessed by contrast ventriculography. Twenty one patients (7\%) had previous coronary artery bypass grafting. Before intervention, 197 patients (63\%) had grade III or IV angina assessed by the Canadian Cardiovascular Society functional classification. ${ }^{15}$ Multivessel coronary angioplasty was performed in 127 patients (41\%) and multilesion coronary angioplasty in 134 patients (43\%). The occluded vessel was the left anterior descending coronary artery in 162 patients (52\%), the circumflex coronary artery in $43(14 \%)$, the right coronary artery in $100(32 \%)$ and a saphenous vein graft in seven patients $(2 \%)$. The lesion was located in the proximal segment of the coronary artery in $40 \%$, the middle segment in $48 \%$ and the distal segment in $12 \%$.

\section{METHODS AND DEFINITIONS}

The baseline clinical characteristics on all 312 patients were recorded. Details from the angiograms taken before angioplasty on 264 patients $(85 \%)$ were assessed by two independent observers without knowledge of procedural outcome. Hand held callipers were used for measuring distances and diameters from the projected angiographic film using the image of the guide catheter to assess the scale of magnification.

The clinical indices analysed as possible determinants of procedural success included age, sex, angina grade, extent of coronary artery disease, left ventricular function, estimated duration of occlusion, and whether multivessel or multilesion coronary angio- plasty was performed. The duration of occlusion was estimated either from the date of myocardial infarction in the distribution of the occluded vessel, abrupt worsening of angina pectoris, or information provided by sequential angiograms. Other clinical factors considered were a history of smoking, hypertension, diabetes mellitus, hypercholesterolaemia, previous myocardial infarction, previous coronary artery bypass surgery, and presence of family history.

The angiographic indices analysed included location of lesion, vessel diameter, length of occlusion (estimated in 246 patients in whom the distal extremity of the occlusion could be defined by collateral contrast filling), morphology of the occlusion (a tapered entry configuration at the occlusion as opposed to an abrupt cut off), distance of the occlusion from the coronary orifice, the presence of diffuse disease (at least one stenosis of $>50 \%$ proximal to the occlusion), vessel tortuosity (presence of at least one bend of $>45^{\circ}$ proximal to the occlusion), calcium at the site of the occlusion (radio-opacity present before contrast injection), thrombus at the site of the occlusion (presence of intraluminal filling defect or contrast staining within the lumen), a side branch at the occlusion, presence of bridging collaterals (multiple small collateral channels bridging the angiographic gap found outside the perceived lumen of the vessel), and whether distal vessel opacification was present.

Procedural success was defined as less than $50 \%$ residual diameter stenosis at the dilated sites. A major in hospital complication was defined as the occurrence of either death, myocardial infarction, or emergency coronary artery bypass grafting.

\section{STATISTICAL METHODS}

Continuous variables are expressed as mean (SD) except estimated duration of occlusion due to its highly skewed distribution. The study patients were divided into subgroups according to procedural outcome. The angiographic and clinical indices analysed as possible determinants of procedural success were compared between these patient groups. Categorical variables between patient groups were compared with the $\chi^{2}$ test or Fisher's exact test and continuous variables were compared with the unpaired $t$ test. The $\chi^{2}$ test for trend was used to test for an association between time period and procedural success rate. A p value of $<0.05$ was considered significant. All indices found to be significantly related to procedural outcome by univariate analysis were included in a multiple logistic regression analysis. The backwards stepwise selection procedure was used to identify independent predictors of procedural outcome significant at the $1 \%$ level (with BMDP program LR). ${ }^{16}$ An equation was developed that best classified the chances of procedural success. The procedural success rates found were examined separately for patients whose predicted probability of success was low $(<30 \%)$, intermediate $(30 \%$ to $69 \%)$, or high $(\geqslant 70 \%)$. 
Table 1 Clinical factors related to procedural outcome for all 312 patients

\begin{tabular}{|c|c|c|c|}
\hline & $\begin{array}{l}\text { Procedural success } \\
(n=191) \\
n(\%)\end{array}$ & $\begin{array}{l}\text { Procedural failure } \\
(n=121) \\
n(\%)\end{array}$ & p Value \\
\hline $\begin{array}{l}\text { Age (mean (SD)) (yr) } \\
\text { Men } \\
\text { Angina grade III/IV } \\
\text { Previous MI } \\
\text { EF < 45\% } \\
\text { Smoking } \\
\text { Hypertension } \\
\text { Family history } \\
\text { Diabetes mellitus } \\
\text { Hypercholesterolaemia } \\
\text { Previous CABG } \\
\text { Multivessel disease } \\
\text { Multivessel PTCA } \\
\text { Multilesion PTCA } \\
\text { Duration of occlusion } \\
>3 \text { months } \\
\text { Lesion location: } \\
\text { LAD } \\
\text { CX } \\
\text { RCA } \\
\text { SVG }\end{array}$ & $\begin{array}{r}55(9) \\
165(86) \\
127(66) \\
126(66) \\
84(44) \\
115(60) \\
41(21) \\
84(44) \\
15(8) \\
90(47) \\
12(6) \\
105(55) \\
80(42) \\
89(47) \\
114(64)\end{array}$ & $\begin{array}{r}56(10) \\
102(84) \\
70(58) \\
79(65) \\
55(45) \\
74(61) \\
33(27) \\
61(50) \\
7(6) \\
47(39) \\
9(7) \\
92(76) \\
47(39) \\
45(37) \\
80(78)\end{array}$ & $\begin{array}{l}\text { NS } \\
\text { NS } \\
\text { NS } \\
\text { NS } \\
\text { NS } \\
\text { NS } \\
\text { NS } \\
\text { NS } \\
\text { NS } \\
\text { NS } \\
\text { NS } \\
\text { p< } 0.001 \\
\text { NS } \\
\text { NS } \\
p=0.02\end{array}$ \\
\hline
\end{tabular}

^Available only in 281 patients.

$\mathrm{CABG}$, coronary artery bypass grafting; $\mathrm{CX}$, circumflex coronary artery; $\mathrm{EF}$, ejection fraction; $\mathrm{LAD}$, left anterior descending artery; MI, myocardial infarction; PTCA, percutaneous transluminal coronary angioplasty; RCA, right coronary artery; SVG, saphenous vein graft.

Predicted probabilities of success were estimated by the jacknife method to compensate for the fact that the same data were being used to test the prediction rule as had been used to derive it.

\section{Results}

\section{ACUTE RESULTS}

Procedural success was achieved in 191 lesions $(61 \cdot 2 \%)$ and did not differ significantly by location of the occlusion $(p=0.06$, table 1 ). The procedural success rate was $56 \%$ for the first 104 cases, $57 \%$ for the next 104 cases, and $71 \%$ for the last 104 cases $(p=0.02)$. The most common cause of failure was inability to pass the guide wire across the occlusion (96 of 121 lesions). Failure to cross the lesion or dilate it with a balloon catheter accounted for 25 of the failures. The procedural success rate was highest for occlusions less than three months old (74\%), intermediate for occlusions between three and 12 months old $(64 \%)$, and least for occlusions greater than 12 months old (47\%).

Six patients $(1.9 \%)$ had one or more major in-hospital complications. One procedural

Table 2 Angiographic data related to procedural outcome for 264 patients

\begin{tabular}{lccl}
\hline & $\begin{array}{l}\text { Procedural success } \\
(n=159) \\
n(\%)\end{array}$ & $\begin{array}{l}\text { Procedural failure } \\
(n=105) \\
n(\%)\end{array}$ & $p$ Value \\
\hline Calcium at occlusion & $24(15)$ & $23(22)$ & NS \\
Thrombus at occlusion & $14(9)$ & $3(3)$ & NS \\
Tapered entry configuration & $121(76)$ & $55(52)$ & NS \\
Vessel tortuosity & $44(28)$ & $27(26)$ & $=0.01$ \\
Side branch at occlusion & $76(48)$ & $67(64)$ & NS \\
Diffuse disease proximal & $20(13)$ & $16(15)$ & $<0.001$ \\
$\quad$ to occlusion & $95(60)$ & $36(34)$ & NS \\
Vessel diameter $>3$ mm & $44(28)$ & $41(39)$ & NS \\
Presence of distal vessel opacification & $10(6)$ & $41(39)$ & NS \\
Bridging collaterals & $33(18)$ & $30(17)$ & \\
Mean (SD) distance of occlusion & $12(11)$ & $12(8)$ & \\
from orifice (mm) & & &
\end{tabular}

*Available only in 246 patients. death $(0.3 \%)$ occurred in a patient who had an apparently uncomplicated coronary angioplasty to the left anterior descending artery and the right coronary artery, which was chronically occluded. He developed ST segment elevation in the anterior chest leads 12 hours after the procedure then recurrent ventricular fibrillation and failed to respond to intensive resuscitation. Five patients $(1 \cdot 6 \%)$ needed emergency coronary artery bypass grafting after failure to recanalise the occluded vessel; three had a coronary dissection (left anterior descending artery in two patients and left main coronary in one) as a result of guide catheter or guide wire trauma, and two developed cardiac tamponade from coronary artery perforation. Of these, one $(0.3 \%)$ also had a $Q$ wave myocardial infarction.

DETERMINANTS OF PROCEDURAL SUCCESS

The clinical characteristics (table 1) and angiographic data (table 2) were analysed to assess their association with procedural outcome. Univariate analysis of 27 clinical and angiographic factors showed that procedural outcome was significantly related to six variables. Procedural success was less common in patients with multivessel disease than in those with single vessel disease $(53 \% v 75 \%$, $\mathrm{p}<0.001$ ), with lesions occluded for more than three months than those occluded for less than three months $(59 \%$ v $74 \%, \mathrm{p}=$ 0.02 ), with vessels less than $3 \mathrm{~mm}$ than those greater than $3 \mathrm{~mm}$ in diameter $(48 \% v 73 \%$, $\mathrm{p}<0.001$ ), with occlusions without a tapered entry configuration ( $43 \% v 69 \%, \mathrm{p}<0.001$ ), with lesions with side branches $(53 \% v 69 \%$, $\mathrm{p}=0.01$ ), and with lessions with bridging collaterals $(20 \% v 70 \%, \mathrm{p}<0.001)$.

Multiple stepwise logistic regression analysis identified the presence of bridging collaterals $(p<0.001)$, the absence of a tapered entry configuration $(p<0.001)$, duration of occlusion of more than three months $(p=0.001)$, and vessel diameter of $<3 \mathrm{~mm}$ $(p=0.003)$ as independent predictors of procedural failure (table 3 ). Neither of the other variables analysed contributed significantly to this regression model. With this model, the estimated probability of procedural success (p) is: $\mathrm{p}=\mathrm{e}^{\mathrm{y}} /\left(1+\mathrm{e}^{\mathrm{y}}\right)$ where $\mathrm{e}=2 \cdot 72$, and $y=-2.56 \times$ bridging collaterals $)+(1.29$ $\times$ tapered entry configuration $)+(-1.35 \times$ duration of occlusion $)+(1.00 \times$ vessel diameter) +0.82 .

Bridging collaterals were scored 1 for presence and 0 for absence; tapered entry configuration was scored 1 for presence and 0 for absence; duration of occlusion was scored 1 for $>$ three months and 0 for $\leqslant$ three months; vessel diameter was scored 1 for $>3 \mathrm{~mm}$ and 0 for $\leqslant 3 \mathrm{~mm}$. The estimated probability of procedural success from the logistic regression model was used to classify patients into groups of high, intermediate, and low probability of procedural success with cut off points of $70 \%$ and $30 \%$ (table 4 ). With the jacknife method, the predictive value for procedural success (where the prob- 
Table 3 Multiple logistic regression model to predict procedural success

\begin{tabular}{lclcr}
\hline Variable & Coefficient & $S E$ & $\chi^{2}$ value & p Value \\
\hline Bridging collaterals & -2.56 & 0.45 & 41.4 & $<0.001$ \\
Tapered entry configuration & 1.29 & 0.34 & 15.1 & $<0.001$ \\
Duration of occlusion $>$ 3 months & -1.35 & 0.44 & 10.8 & 0.001 \\
Vessel diameter $>3$ mm & 1.00 & 0.33 & 9.16 & 0.003 \\
Constant & 0.82 & 0.48 & 3.06 & 0.080 \\
\hline
\end{tabular}

Analysis was based on 236 patients with complete clinical and angiographic data.

Table 4 Patients classified by observed success and predicted probability of success

\begin{tabular}{|c|c|c|c|c|}
\hline & \multicolumn{3}{|c|}{ Predicted probability of success } & \multirow[b]{2}{*}{ Tota } \\
\hline & $<30 \%$ & $30-69 \%$ & $\geqslant 70 \%$ & \\
\hline $\begin{array}{l}\text { Observed success } \\
\text { Observed failure } \\
\text { Patients (n) } \\
\text { Predictive value for } \\
\text { procedural success (\%) }\end{array}$ & $\begin{array}{r}7 \\
29 \\
36 \\
-\end{array}$ & $\begin{array}{r}56 \\
49 \\
105 \\
-\end{array}$ & $\begin{array}{r}86 \\
9 \\
95 \\
91\end{array}$ & $\begin{array}{r}149 \\
87 \\
236 \\
-\end{array}$ \\
\hline $\begin{array}{l}\text { Predictive value for } \\
\text { procedural failure (\%) }\end{array}$ & 81 & - & - & - \\
\hline
\end{tabular}

ability for success $\geqslant 70 \%$ ) was $91 \%$ ( $95 \%$ CI $83 \%$ to $96 \%$ ) and predictive value for procedural failure (where the probability for success $<30 \%$ ) was $81 \%$ (95\% CI $64 \%$ to $92 \%)$. One hundred and five patients (44\%) had an intermediate predicted probability of success (where the probability for success was $30 \%$ to $69 \%$ ). Thus the model successfully identified two groups, accounting for $56 \%$ of the lesions, as having an unusually high $(\geqslant 70 \%)$ or low $(<30 \%)$ likelihood of procedural success.

\section{Discussion}

During the early years of percutaneous transluminal coronary angioplasty, a total occlusion was considered an absolute contraindication to the procedure. ${ }^{17}$ Evidence that left ventricular function may improve after recanalisation of chronic total occlusions $^{18}$ and the perception that procedural failure is not associated with an adverse outcome $^{19}$ provided the impetus for its increasing application. In the most recent coronary angioplasty registry report from the National Heart, Lung, and Blood Institute, chronic total occlusions accounted for $10 \%$ of all attempted coronary angioplasties during the period $1985-6 .{ }^{9}$

The procedural success rate per lesion of $62 \cdot 1 \%$, mortality of $0.3 \%$, myocardial infarction rate of $0.3 \%$, and incidence of emergency coronary artery bypass grafting of $1.6 \%$ in this study are comparable with previous studies. Other studies have reported procedural success rates ranging from $53 \%$ to $73 \%$ depending on the inclusion criteria, ${ }^{4-6}$ mortalities from $0 \%$ to $1 \cdot 1 \%, 51219$ myocardial infarction rates from $0 \%$ to $2 \cdot 1 \%, 5620$ and emergency bypass surgery rates from $0 \%$ to $8.9 \% .^{519} 20$ The differences in the success rates between the various studies probably reflect differences in the selection criteria of patients for coronary angioplasty of chronic total occlusion. A lesion would have been selected only if the operator considered that the occlusion could be recanalised with a reasonable chance of success. Hence the success rates reported may have differed if dilatations of all total occlusions were attempted. Although the procedural success rate was lower than coronary angioplasty of non-occluded lesions, recanalisation of chronic total occlusion was associated with fewer complications. This low risk of acute complications has also been shown by previous studies. ${ }^{51219}$ The safety, however, is neither absolute nor a consistent finding. The most recent report from the National Heart, Lung, and Blood Institute showed a similar incidence of major complications occurring during coronary angioplasty of total and sub-total occlusions. ${ }^{21}$ In our study, complications often occurred directly as a result of the procedure itself, either from guide catheter or guide wire trauma causing coronary dissection or perforation. The one procedural death was related to acute vessel closure in a non-occluded vessel after an uncomplicated multivessel coronary angioplasty in a patient with impaired left ventricular function.

An improved success rate was found with the last 104 cases attempted in this study. Similar improvements in success rate with subsequent attempts at dilating chronic total occlusions have been reported by other investigators. ${ }^{12}$ This may be attributed to improved selection of cases, improved operator experience and angioplasty technique, and evolution of equipment. These developments occurred in parallel and it would be difficult to attribute the improved success rate to any single variable. Improved selection of patients may have arisen as a result of knowledge gained from previous published reports on coronary angioplasty of chronic total occlusion. In our study, more than $60 \%$ of the procedures were performed by a single operator, who also often assisted the more junior operators when they failed to recanalise the occluded artery. Therefore, the impact of operator experience on success rate cannot be assessed accurately. Stone et al have shown no clear correlation between the number of dilatations of total occlusions attempted and the procedural success rate. ${ }^{12}$ Despite the introduction of new angioplasty technology such as laser angioplasty ${ }^{22}$ and low speed rotational angioplasty, ${ }^{23}$ the approach to coronary angioplasty of a total occlusion has remained essentially unchanged at our institution. Most procedures in our study were performed with conventional systems. The combination of improved balloon angioplasty equipment (guide catheters with better support, guide wires of varying stiffness, and low profile balloon catheters) and improved techniques (deep guide catheter engagement, advancing the balloon dilatation catheter to the totally occluded arterial segment to splint the guide wire) have increased the likelihood of crossing and dilatation of the occluded segment. Few cases involved the use of specially designed catheters ${ }^{6}$ or the Magnum-Meier 
system. ${ }^{14}$ Thus the impact of these specially designed pieces of angioplasty equipment is difficult to assess in the presented study cohort. Even with specially designed catheters, ${ }^{6}$ the reported overall success rate for coronary angioplasty of total occlusion was no higher than $73 \%$ and may not be superior to conventional systems. ${ }^{24}$ Preliminary results comparing the MagnumMeier system with the conventional technique have shown contradictory results ${ }^{24}$ ${ }^{25}$ and other new technology such as laser angioplasty ${ }^{22}$ and low speed rotational angioplasty ${ }^{23}$ will need further clinical evaluation.

Given the increasing use of coronary angioplasty to recanalise chronic total occlusions ${ }^{9}$ and the lower primary success rate, ${ }^{4-6}$ the ability to predict accurately the likelihood of procedural success will have important implications in selecting cases for coronary angioplasty. In this study, multiple logistic regression analysis identified the presence of bridging collaterals, absence of a tapered entry configuration, a longer duration of occlusion, and a smaller vessel diameter as independent predictors of procedural failure. The influence of vessel size has not been previously reported but the other indices have been shown to predict procedural failure in some studies. Bridging collaterals, which represent dilated vasa vasorum, ${ }^{26}$ might divert the guide wire during coronary angioplasty. As a result of their fragility, they perforate easily if touched by a guide wire. The presence of bridging collaterals as a predictor of procedural outcome has been shown by some $^{12}$ but not all previous studies. ${ }^{511} \mathrm{~A}$ tapered entry configuration assists in guide wire placement thus providing guide wire stability, increases the chance of finding the correct channel, and allows axial force to be transmitted directly to the distal lumen. Its influence on procedural outcome is confirmed by some ${ }^{12} 20$ but not other studies. ${ }^{4511}$ The duration of occlusion may determine the histological components of the occluded segment and influence the ability of a guide wire to cross the lesion. The longer the duration, the more the lesion is organised with fibrous tissue and the likelihood of recanalisation becomes less. In some ${ }^{41927}$ but again, not all previous studies, 51112 the estimated duration of occlusion was related to procedural outcome. This inconsistent finding may be partly explained by the difficulty and inherent limitation of estimating the duration of occlusion from clinical information. A larger vessel diameter may allow a greater margin of error during the passage of the guide wire across the occluded segment into the distal intraluminal course if the guide wire deviates from the main vessel axis. Hence the likelihood of the guide wire creating subintimal pathways by getting underneath a plaque is reduced in a larger vessel as opposed to a small diameter vessel where a small deviation from its main axis could cause the guide wire to leave its intraluminal course, create a subintimal pathway, and thereby pursue an intramural course. There were also more unsuccessful dilatations in patients who had multivessel disease and in lesions with side branches although these factors did not reach statistical independence in the multivariate model. The presence of distal vessel opacification did not emerge as an important determinant of procedural success in our study, as was shown by some investigators. ${ }^{1112}$ Others, however, have reported conflicting results. ${ }^{427}$ The differences may be accounted for by the different underlying mechanisms that have caused the distal vessel opacification seen in the various study populations. These mechanisms include spontaneous recanalisation of the occlusion, subtotal occlusions, collaterals, and a combination of these. ${ }^{28}$

Apart from the presence of bridging collaterals which reduces the overall probability of procedural success to $20 \%$, however, the presence of the other variables in isolation should not deter attempts to recanalise chronic occlusion. In the presence of favourable angiographic indices, even occlusions of over a year old can be dilated with a procedural success rate approaching $50 \%$ with an acceptable complication rate. In this study, a model for predicting probability of procedural success was developed with stepwise logistic regression analysis that combined these clinical and angiographic variables. This model identified $56 \%$ of the lesions as having a procedural success rate that differed considerably from the data base mean of $61 \cdot 2 \%$; 95 lesions were classified as having a high chance of procedural success and had an actual success rate of $91 \%$, whereas 36 were classified as having a low chance of procedural success and had an actual success rate of $19 \%$. The remaining 105 lesions that were classified as having an intermediate predicted probability of procedural success had an actual success rate of $53 \%$.

Thus the described model may assist in the selection of chronic total occlusions for potential angioplasty with those of low likelihood of success treated by an alternative mode of revascularisation.

\section{STUDY LIMITATIONS}

This study is a retrospective analysis of data and is subject to the limitations inherent in any retrospective study. The frequency of occurrence of some of the angiographic indices analysed were low. Thrombus was present in only 17 and calcium in only 47 of the 264 coronary angiograms included in the analysis. These indices may become significant determinants of procedural success if a greater number of patients were available in the study. Also, although the model was developed from a large data base and validated on the database from which it was derived with the jacknife method, it needs to be tested prospectively and against other populations. We are currently collecting new data for this purpose.

\section{CONCLUSIONS}

This study confirms previous reports that 
coronary angioplasty of chronic total occlusions is associated with a low risk of acute complication. It has also shown that procedural success is adversely influenced by easily identifiable clinical and angiographic features. Although further prospective validation is necessary, the multiple logistic regression model described may help clinicians assess the suitability of coronary angioplasty in individual patients with chronic total occlusions.

1 Gruentzig AR. Transluminal dilatation of coronary artery stenosis [letter]. Lancet 1978;1:263.

2 Savage R, Hollman J, Gruentzig AR, King S III, Douglas $J$, Tankersley $R$. Can percutaneous transluminal coronary angioplasty be performed in patients with total occlusion [abstract]? Circulation 1982;66(suppl II):II330.

3 Heyndrickx GR, Serruys PW, van den Brand M, Vandormael M, Reiber JHC. Transluminal angioplasty after mechanical recanalization in patients with chronic occlusion of coronary artery [abstract]. Circulation 1982;66(suppl II):II-5

4 Kereiakes DJ, Selmon MR, McAuley BJ, McAuley DB, Sheehan DJ, Simpson JB. Angioplasty in total coronary artery occlusion: experience in 76 consecutive patients. f Am Coll Cardiol 1985;6:526-33.

5 Bell MR, Berger PB, Bresnahan JF, Reeder GS, Bailey $\mathrm{KR}$, Holmes DR Jr. Initial and long-term outcome of 354 patients after coronary balloon angioplasty of total coronary artery occlusions. Circulation 1992;85: 1003-11.

6 Hamm CW, Kupper W, Kuck K-H, Hoffman D, Bleifeld W. Recanalization of chronic, totally occluded coronary arteries by new angioplasty systems. Am $\mathcal{f}$ Cardiol arteries by new

7 Bell MR, Bailey KR, Reeder GS, Lapeyre AC III, Holmes DR Jr. Percutaneous transluminal coronary angioplasty in patients with multivessel disease: how important is in patients with multivessel disease: how important is complete revascularization for cardiac
vival? $₹ \mathrm{Am}$ Coll Cardiol 1990;16:553-62.

8 Deligonul U, Vandormael MG, Kern MJ, Zelman R, Galan K, Chaitman BR. Coronary angioplasty: a therapeutic option for symptomatic patients with two and three vessel coronary disease. $\mathcal{F} \mathrm{Am}$ Coll Cardiol 1988;11: 1173-9.

9 Deitre K, Holubkov R, Kelsey S, et al. Percutaneous transluminal coronary angioplasty in 1985-1986 and 1977-1981: the National Heart, Lung, and Blood Institute Registry. $N$ Engl F Med 1988;318:265-70.

10 DiSciascio G, Vetrovec GW, Cowley MJ, Wolfgang TC. Early and late outcome of percutaneous transluminal coronary angioplasty for subacute and chronic total coronary occlusion. Am Heart $\mathcal{F} 1986 ; 111: 833-9$.

11 LaVeau PJ, Remetz MS, Cabin HS, Hennecken JF, McConnell SH, Rosen RE, Cleman MW. Predictors of success in percutaneous transluminal coronary angiosuccess in percutaneous translumina coronary angio-
plasty of chronic total occlusions. Am $¥$ Cardiol 1989;64: plasty of

12 Stone GW, Rutherford BD, McConahay DR, Johnson
WL Jr, Giorgi LV, Ligon RW, Hartzler GO. Procedural outcome of angioplasty for total coronary artery occlusion: an analysis of 971 lesions in 905 patients. 7 Am Coll Cardiol 1990;15:849-56.

13 Sowton E, Timmis AD, Crick JCP, Griffin B, Yates AK, Deverall $P$. Early results after percutaneous transluminal coronary angioplasty in 400 patients. Br Heart $f$ 1986;56:115-20.

14 Meier B, Carlier M, Finci $L$ Nukta $E$ Urban $P$, Niederhauser W, Favre J. Magnum wire for balloon Niederhauser W, Favre J. Magnum wire for balloon 7 Cardiol $1989 ; 64: 148-54$

15 Campeau L. Grading of angina pectoris. Circulation 1976 54:522-3

16 Dixon WJ, Brown MB, Engelman L, Jennrich RI. BMDP Statistical Software Manual. University of California Press 1990;2:1013-45.

17 Kent KM, Bentivoglio LG, Block PC, et al. Percutaneous transluminal coronary angioplasty: report from the Registry of the National Heart, Lung and Blood Institute. Am F Cardiol 1982;49:2001-2020.

18 Melchior JP, Doriot PA, Chatelain P, Meier B, Urban P, Finci $L$, Rutishauser $W$. Improvement of left ventricular contraction and relaxation synchronism after recanalization of chronic total coronary occlusion by angioplasty $\Im$ Am Coll Cardiol 1987;4:763-8.

19 Melchior IP, Meier B, Urban P, Finci L, Steffenino G Nobel J, Rutishauser W. Percutaneous transluminal coronary angioplasty for chronic total coronary artery coronary angioplasty for chronic total

20 Ivanhoe RJ, Weintraub WS, Douglas JS Jr, Lembo NJ, Furman M, Gershony G, et al. Percutaneous transluminal coronary angioplasty of chronic total occlusions: primary success, restenosis, and long-term clinical follow-up. Circulation 1992;85:106-15.

21 Ruocco NA Jr, Ring ME, Holubkov R, Jacobs AK, Detre KM, Faxon DP. Results of coronary angioplasty of chronic total occlusions (the National Heart, Lung, and Blood Institute 1985-1986 Percutaneous Translumina Angioplasty Registry). Am ₹ Cardiol 1992;69:69-76.

22 Cumberland DC, Belli AM, Oakley GDG, et al. "Laser wire" for percutaneous angioplasty complete peripheral and coronary arterial occlusions: initial clinical results [abstract]. ₹ Am Coll Cardiol 1989;13:60A

23 Kaltenbach $M$, Vallbracht $C$. Low speed rotational angioplasty: applicability to chronic coronary artery obstrucplasty: applicability to chronic coronary artery obstrions

24 Haerer W, Schmidt A, Eggeling T, Hoher M, Kochs M Hombach V. Angioplasty of chronic total occlusions: results of a controlled randomized trial [abstract]. $\mathcal{F} A m$ Coll Cardiol 1991:17:113A.

25 Meier B, Urban $\mathbf{P}$, Muller $T$, Villavicencio $R$, Dorsaz $P$, Favre J. Randomized comparison between Magnum and standard systems for balloon recanalisation of chronic total coronary occlusions [abstract]. Eur Heart $\mathcal{f} 1990$ 11(suppl): 21 .

26 Barger AC, Beeuwkes R III, Lainey LL, Silverman KJ Hypothesis: vasa vasorum and neovascularization of human coronary arteries. $N$ Engl $7 \mathrm{Med}$ 1984;310: $175-8$.

27 Serruys PW, Umans V, Heyndrickx GR, van den Brand $M$, de Feyter PJ, Wijns W, et al. Elective PTCA of totally occluded totally occluded results. Eur Heart $f$ 1985;6:2-12.

28 Meier B. Cur Heart f 1985;6:2-12. of interventional cardiology. Philadelphia: WB Saunders, of interventional 